\title{
ABORDAJE CONCEPTUAL SOBRE COMUNICACIÓN Y GÉNERO EN EDUCACIÓN
}

\author{
Ana Lucía Villarreal Montoya
}

Recibido 28-II-2002

西

Aceptado 14-V-2002

\begin{abstract}
Resumen: Este artículo se origina en el desarrollo conceptual que se realiza como parte del proyecto de investigación "Comportamiento Comunicacional de hombres y mujeres en el proceso educativo”, el cual está en ejecución, adscrito al Programa de Investigación en Educación y Género (PIEG), en el Instituto de Investigaciones para el Mejoramiento de la Educación Costarricense (IIMEC), de la Facultad de Educación de la Universidad de Costa Rica.

El objetivo general de la investigación consiste en analizar y visibilizar cómo se comunican y relacionan las actoras y los actores del proceso educativo, según su sexo/género, tanto en los espacios formales como informales en los cuales se desarrolla dicho proceso.
\end{abstract}

\section{Paradigma en que se inscribe}

A inicios del tercer milenio se ha demostrado que el paradigma (patriarcal) que planteaba el desarrollo como una meta únicamente de crecimiento económico, no logró satisfacer todas las necesidades de los seres humanos, por lo cual se está en la búsqueda y construcción de nuevas propuestas, una de ellas es la del paradigma de desarrollo humano, también llamado ecológico, y que como uno de sus principios plantea retomar los valores femeninos, como una forma de lograr la formación de seres humanos integrales, por ello la presente investigación se ubica en este paradigma.

"El enfoque de desarrollo humano sustentable se ha centrado en construir los caminos de acceso de las personas a condiciones sociales, económicas, políticas, jurídicas y culturales que les permitan participar y contar con educación, salud, techo y alimentación de calidad, así como acceder al trabajo y realizar diversas actividades, y poseer bienes... Es esta una perspectiva de redistribución de la riqueza material y simbólica y de su cuidado, preservación e incremento... Sus principios metodológicos y su sentido son: la democracia, la seguridad y condiciones de paz y convivencia solidaria.” (Lagarde: 1996; 103-104).

En el desarrollo de la comunicación como relación se retoman los principios metodológicos citados y se busca validar y construir propuestas educativas con estos principios, desde el campo de la comunicación. Con lo cual se pretende aportar para la superación del patriarcado ya que este: 
“... no se puede superar haciendo patriarcas a quienes no lo son, para que todes tengan los derechos formales y reales del patriarca, sino superando ese orden social, con su régimen de derechos. Aquello a lo que se denomina derechos, en la práctica es un sistema de privilegios y el privilegio remite necesariamente a su otra cara, que es la deposición. Derechos/privilegios para unes es deposición para otres”. (Izquierdo: 1991; 80)

Ante esta situación se adopta el modelo de ciencia con visión feminista, el cual tiene más que ver con los valores que ahora se asignan a lo femenino, ya que las relaciones que establecen las mujeres con los objetos de estudio son de mutualidad, más que dominación/subordinación. "De ahí se deriva un modelo de interrelación que es contrapuesto al dicotómico..." (Sánchez: 1991; 173).

Esta misma autora especifica que la ciencia feminista sería una ciencia en la que la indeterminación no fuera causa de angustia y que -debido a la capacidad de relacionarse con las diferencias- provocara búsquedas y caminos diversos. La dominación sobre la naturaleza se convertiría en actuación en la naturaleza, como parte que somos de aquel todo omniabarcador. Una ciencia que conviviría en definitiva con el inacabamiento, la multifinalidad, la incertidumbre, la diferencia, la ambigüedad.

\section{La comunicación se concentra en el aula en tres aspectos: Lenguaje, Relaciones y Espacio}

En las búsquedas que se han realizado, tanto en Internet como en las bibliotecas nacionales, el concepto de comunicación en educación implícito es el de lenguaje, información masiva o el uso de las nuevas tecnologías en los procesos educativos; invisibilizándose la comunicación como relación/interrelación, que es la que se desarrolla mayoritariamente en la vida de los seres humanos.

El comprender el proceso educativo como un fenómeno social, que debe ser democrático y participativo y que debe ir superando los enfoques y las prácticas tradicionales; implica que se relacionen con dos fenómenos importantes para el desarrollo de la educación dentro de un marco democrático: la comunicación y el espacio, o sea, el cómo y el dónde se desarrollan esos procesos educativos.

Por ello se lleva a cabo un proceso de construcción teórico/metodológica del concepto comunicación y en principio se propone que esta se concreta en el aula en tres aspectos: lenguaje, relaciones/interrelaciones y uso y distribución del espacio.

Se considera que este es un aporte a destacar de esta investigación, ya que implica el tomar aportes de disciplinas y autores diversos y construir con ellos una propuesta específica del concepto de comunicación en la educación, el cual se puede ajustar y ampliar a otras áreas.

\section{Lenguaje}

Tradicionalmente cuando hablamos de comunicación nos remitimos al lenguaje, como una de las formas por excelencia de este proceso.

La palabra lenguaje se define como "Conjunto de sonidos articulados con que el hombre manifiesta lo que piensa y siente" (Real Academia de la Lengua: 1994; 878). Además de la utilización del masculino como término genérico, el lenguaje es reducido a la oralidad de los seres humanos.

Sobre este tema existen múltiples investigaciones y construcciones teórico metodológicas, algunas de las cuales serán retomadas; como por ejemplo la de María Ángeles Calero, quien afirma que en las sociedades patriarcales los sistemas lingüísticos presentan una marcada óptica masculina, es lo que se llama androcentrismo, el cual supone que la medida de todas las cosas se toma de los varones y que, en el caso de que las mujeres sean consideradas, son tratadas siempre como una desviación o alejamiento de la norma, construida ésta sobre los patrones masculinos. 
Por lo cual, dice, el androcentrismo acarrea, sin duda, la infravaloración y hasta la ocultación de lo femenino y puede ir acompañado, además, de un componente misógino (Calero: 1999; 9).

Fenómeno que es constatado por Chaves $(2001 ; 25)$ “... el lenguaje que utilizó la profesora, sobre todo al iniciar el curso lectivo, fue un lenguaje dirigido al control real y simbólico de los estudiantes y las estudiantes, el interés se dirigió a comunicar las reglas de la clase y a que ellos y ellas las cumplieran de acuerdo con la función reproductora de la escuela, que se ajusta a los requerimientos de la producción económica y cultural dominante".

Por su parte Jiménez $(2000 ; 31)$ expresa que "El lenguaje como institución patriarcal es sexista y opresor en sí mismo". Afirmación que fue antecedida por Freire al expresar que hablar del cuño machista del lenguaje no es un problema gramatical, sino ideológico y especifica "La discriminación de la mujer, expresada y efectuada por el discurso machista y encarnada en prácticas concretas, es una forma colonial de tratarla, incompatible por lo tanto con cualquier posición progresista, de mujer o de hombre, poco importa"; y expresa que cambiar el lenguaje es parte del proceso de cambiar el mundo, ya que la relación lenguaje-pensamiento-mundo es una relación dialéctica, por lo cual la superación del discurso machista, como la superación de cualquier discurso autoritario, exige o nos plantea la necesidad de empeñarnos en prácticas también democráticas (1998; 64).

El sexismo se concreta tanto en la invisibilización o reproducción de estereotipos femeninos, como en la reproducción de estereotipos masculinos. Según Izquierdo (1991; 82) la conducta sexista consiste en prejuzgar la existencia de distintas capacidades en función de las diferencias anatómicas y fisiológicas de las hembras y los machos, se trata de un prejuicio.
Parte de la crítica feminista que se ha hecho en la investigación sobre sexismo en la lengua castellana en España es resumida por Ana Mañeru Méndez (1991; 19) en los siguientes aspectos:

- La preeminencia masculina de las culturas favorece que los niños aprendan que su discurso está legitimado por su posición de futuros hombres, y que las niñas aprendan un discurso subordinado a otros intereses que no son los suyos, por su posición de futuras mujeres.

- Respecto al sexismo, las normas de uso del lenguaje operan siempre en un sentido y no en otro, lo cual excluye la posibilidad de que dichas normas sean casuales o indiferentes.

- Cada vez que se utilizan estas normas o se transmiten a través de los procesos educativos, sin someterlas a la crítica, se colabora a perpetuar la discriminación.

- $\quad$ El lenguaje no es abstracto, ajeno a las personas, sino un instrumento que debe responder a su capacidad de pensamiento y comunicación, sin coartarla.

- La valoración diferente del discurso masculino y femenino es un reflejo evidente de una ideología sexista.

- $\quad$ El lenguaje sexista es un instrumento de discriminación en sí mismo, que actúa contribuyendo a enmascarar la discriminación que produce y la propia realidad discriminatoria subyacente.

Además, se analizará la lengua, como fondo colectivo común, porque como se ha afirmado esta también representa un rol en las relaciones de poder y en los procesos de valorización social, de manera que ciertos usos, percibidos como característicos de los grupos dominantes, son más apreciados y tienden a ser adoptados por las otras capas sociales (Vásquez: 1996; 58). 


\section{Relaciones/interrelaciones}

Aunque tradicionalmente se reduce la comunicación al lenguaje, en esta investigación se retoma la comunicación como relación e interrelación entre las personas. Este planteamiento se sustenta en las siguientes proposiciones:

a. En la sociedad patriarcal las relaciones entre hombres y mujeres son de poder, de dominación/subordinación, $\mathrm{y}$ estas se reproducen en todas las estructuras e instituciones de la sociedad, no siendo la educación una excepción. Así como de que este tipo de relaciones son asumidas por hombres y mujeres, según el rol que estén desempeñando.

En este eje se analizarán las conductas de todos los actores, así como las relaciones que se dan en los procesos educativos y cómo éstas corresponden con determinados modelos de educación, los cuales tienen implícitos modelos de comunicación específicos para cada uno de ellos.

b. Se retomará la propuesta de Pearce (1994) en el sentido de que la comunicación en actividades (conversaciones, actividades conjuntas, semejantes a juegos), es el medio constructivo, en tanto el lenguaje es una parte de esas actividades. Este autor plantea que el viejo paradigma era en gran medida un paradigma ligado a la divulgación escrita de materiales: su noción acerca del conocimiento requería que aquello que se considerara como tal fuera escrito o pudiera serlo. En tanto el nuevo paradigma consiste en el pasaje de la teoría a la praxis; en pasar de espectadores a participantes.

Afirma Pearce $(1994 ; 281)$ que en lugar de aspirar al conocimiento de las cosas verdaderas, tenemos que aspirar a una sabiduría acerca de cómo funcionan las cosas en el mundo; lo cual es algo más que el conocimiento artesanal de cómo se hace algo, implica una inteligencia reflexiva (o una reflexión inteligente).

c. Comunicación no es: sermonear, aconsejar, lanzar advertencias o regaños, hacer pronunciamientos, ni juzgar (Sanford: 1998). Esta afirmación, permitirá identificar estas formas de relacionarse como parte de los procesos de información, no de los de comunicación. Ello por cuanto la persona que se atribuye el poder para sermonear, aconsejar, lanzar advertencias o regaños, hacer pronunciamientos y juzgar, está actuando como emisora privilegiada, o sea se percibe a sí misma como quien sabe más para calificar la conducta $o$ acciones de la otra persona, con lo cual asume el rol de dominación.

d. Según el Interaccionismo las personas no actúan sino que interactúan, lo cual puede ser retomado desde la comunicación, en el sentido de que las personas no se relacionan con los demás, sino que se interrelacionan, esto implica dar el paso de pensar que la comunicación es el fenómeno mediante el cual una persona (emisora) da un mensaje a otra persona (receptor), y replantear la comunicación como un proceso dialógico, de construcción conjunta, entre personas que aunque desempeñen diferentes roles tienen la capacidad de expresarse y aportar desde sus experiencias y aprendizajes.

La interacción social no se concibe como una simple respuesta de la persona a los factores que están actuando sobre ella, sino como un proceso de construcción que es también formativo. La persona elabora 
esquemas de interpretación que no son nunca definitivos, pero que se confirman y se precisan como consecuencia de su confrontación con las respuestas de otros individuos (Woods 1992, citado por Vásquez: 1996; 46).

La perspectiva interaccionista no concibe al actor (adulto o niño) como un receptor pasivo, ya que este participa activamente en el proceso de su propia socialización, contribuyendo de esta manera en la recreación del sistema social donde vive y actúa, de tal modo que se puede decir que (re)construye la realidad social, dándole un sentido; interacciones que son influenciadas directamente por las situaciones y los contextos donde se desarrollen. Evidentemente, este proceso es el resultado de las interacciones ejecutadas por un conjunto de actores durante períodos de tiempo más o menos largos (Vásquez: 1996; 49).

Esto concuerda con la propuesta de Freire $(1998 ; 135)$ en "Pedagogía del oprimido", donde plantea que "mientras que enseñando unas y aprendiendo otros, todos aprenden y enseñan, sin que esto signifique que sean todos iguales o que quien enseña no aprende o quien aprende no enseña”.

\section{Espacio}

Existe una estrecha relación entre los modelos educativos y los modelos espaciales como contenedores sociales de estas actividades, ya que el uso que se haga del espacio reproduce las relaciones de poder y los modelos de comunicación implícitos en dichas relaciones.

Los actores que representan la institución (especialmente los maestros, pero también los inspectores y los directores de los establecimientos), no tienen conciencia del efecto que tendrá el escenario que han montado y donde actúan cotidianamente (Vásquez: 1996; 51).

Este aspecto será ampliado en el punto E. de este documento, en el cual se desarrollan los modelos espaciales acordes a cada modelo de educación y de comunicación.

\section{Las relaciones de poder patriar- cales dominación/subordinación se reproducen en el aula}

Al igual que en las demás instituciones sociales, las relaciones que se dan en los procesos educativos son de dominación/subordinación y son reproducidas por todas las personas (Villarreal: 1999), siendo determinante el rol de poder que desempeña cada persona para asumir conductas de dominación o subordinación.

"La jerarquía de los géneros conduce al establecimiento de relaciones de dominación/subordinación entre el género masculino y el femenino, independientemente de cuál sea el sexo de las personas que ocupan los espacios sociales de género, en las relaciones de género" (Izquierdo: 1991; 82).

Es muy importante que las personas comprendan que "la perspectiva de los dominantes no es patrimonio sólo de los dominantes; marginadas y oprimidas ven su mundo desde la perspectiva dominante porque es la única que conoce conscientemente" (Nota al pie: Facio: 1994; 30). Esto implica que casi todas las personas de la sociedad patriarcal reproducimos este tipo de relaciones, no tanto porque las conocemos conscientemente -como afirma Facio- sino porque las aprendemos como parte del proceso de socialización, como la forma válida y única de relacionarnos, y las reproducimos inconscientemente, aunque en ocasiones lleguemos a defenderlas conscientemente, lo cual ocurre por el hecho de que el patriarcado tiene su "discurso verdadero", el cual aprendemos como único; ya que esta es una de las formas que tiene para mantenerse y para que quienes vivimos en esta sociedad lo reproduzcamos y nos sintamos identificados con él.

Esta es una de las trampas en las que estamos atrapados y por lo cual es necesario realizar estudios y trabajos de investigación y acciones donde se visibilice este fenómeno y se pongan en práctica 
otras formas de relacionarnos; para ir construyendo formas alternativas a estas conductas.

"El patriarcado obliga a las mujeres que detentan el poder a utilizarlo de la misma manera que los hombres, porque de esta manera se asegura que la gran mayoría de las mujeres no sientan que otra mujer representa sus intereses, porque se inhibe todo sentimiento de sorosidad, fomentándose más bien, la competencia por un hombre" (Facio: 1994; 24).

En el caso específico de la comunicación las relaciones dominación/subordinación se concretan en las conductas comunicacionales agresivas y sumisas, las cuales serán objeto de estudio en el aula.

"El primer aspecto que emerge de los datos es la influencia que tiene la educadora en el proceso de socialización de los niños y las niñas, pues es ella la persona que tiene el mayor poder, es la que establece las reglas del juego dentro del contexto del aula, y la que mediante el lenguaje y las interacciones que propone transmite sistemáticamente actitudes, conocimientos, experiencias, valores, en fin una visión de mundo y de ser humano que va moldeando la identidad de las estudiantes y los estudiantes" (Chaves: 2001; 25).

Por su parte Marta Lamas (1994; 12) expresa que plantear el problema del sexismo y del poder patriarcal en términos de género permite entender que el problema de las mujeres en la sociedad no es un problema de biología, sino un problema social y que el feminismo no es una lucha de y para las mujeres, aunque parte de ellas, sino de toda la sociedad. Esto lo complementa al expresar que lo que el feminismo propone es acabar con la regulación cultural que adjudica ciertas características y funciones a un género, con la consecuente exclusión o limitación del otro y que lo que se quiere es que la riqueza de la gama de posibilidades humanas se exprese sin reglamentaciones.

El Interaccionismo plantea que en el aula se dan dos tipos de interacciones: verticales y horizontales. Las primeras son las que se dan entre el docente o la docen- te y los estudiantes y las segundas entre los estudiantes, pares entre ellos (Vásquez: 1996; 80).

Interacciones verticales: se dan en el marco de una estructura asimétrica en relación con el poder. Uno de los protagonistas (el docente o la docente) representa a la institución, la ley, el poder, el conocimiento y posee la autoridad; mientras que el otro protagonista (alumnado) acepta que no sabe, se encuentra en una posición de sumisión a la institución y no pone en duda a la autoridad. Lo anterior determina que los diferentes actores sociales tengan roles claramente definidos y que sea muy raro que se acepte un cuestionamiento a estos roles, más bien al contrario, ello provocaría sanciones.

Estas interacciones están ritualizadas: el alumno dispone de modelos para dirigirse al maestro y los intercambios que provienen del maestro también se efectúan según un modelo; pero el maestro tiene el derecho de cambiar y de imponer nuevos modelos, siempre que permanezca dentro del marco global que estipula la institución (Vásquez: 1996; 81).

Interacciones horizontales: los protagonistas de estas son pares. Son amplias: se extienden de manera flexible a través del tiempo, pueden reproducirse muchas veces a lo largo de una clase y mucho más aún; la flexibilidad le permite a los actores estar relativamente atentos a la lección al mismo tiempo que entablan interacciones entre ellos. Cuando se observa el conjunto de una clase se puede afirmar que la mayoría del tiempo hay alumnos practicando interacciones horizontales. Aparentemente el maestro no interviene, se desarrollan a pesar suyo, lo cual probablemente les confiere una parte de su atractivo.

En estas interacciones los alumnos desafían una prohibición, por lo cual se trata de un "desafío disimulado". Además, los actores se sitúan todos en una posición equivalente. 
La cultura de la institución impone una cierta interpretación donde estas interacciones se perciben como "marginales" y negativas en relación con lo que se considera como una clase 'bien llevada' (Vásquez: $1996 ; 126)$.

Ambas interacciones (verticales y horizontales) pueden desarrollarse paralela y simultáneamente.

\section{Invisibilización de las mujeres: La mayor violiencia del patriar- cado hacia el género femenino}

Nos hemos -o más bien dicho- nos han enseñando que violencia es sinónimo de agresión y de ejecución de actos que afectan física o psicológicamente a las personas. Pero al consultar bibliografía sobre el tema encontramos varias definiciones que complementan dicho concepto con el de omisión.

Por ejemplo, Claramunt (1997; 4 y 7) define que la violencia emocional es toda acción u omisión destinada a disminuir a la otra persona, lesionando su autonomía y autoestima; y la violencia doméstica como todo acto $u$ omisión que resulte en un daño a la integridad física, sexual, emocional o social de un ser humano. Concuerda con ella Batres, quien define la violencia doméstica como cualquier acto de comisión u omisión, llevado a cabo por miembros de la familia y cualquier condición que resulte de dichos actos y que prive a otros miembros de la familia de iguales derechos y libertades o interfiera con su máximo desarrollo y libertad de elegir.

Con base en las definiciones anteriores podemos afirmar que uno de los mayores actos de violencia ejercidos por la sociedad patriarcal hacia las mujeres es su invisibilización, desde el lenguaje, hasta todos los aportes que las mujeres hemos dado a la humanidad y que han permitido que nos mantegamos como especie, por ejemplo.
Esta invisibilización es reproducida y mantenida día a día por los sistemas educativos. Es así como las niñas, cuando ingresan a los centros educativos, deben acostumbrarse a entender que se les llame "niños", las madres debemos acostumbrarnos a que en las informaciones escritas de las escuelas y en las reuniones de "padres de familia" (a las cuales acuden un 80 ó $90 \%$ de madres y el resto de padres), nos demos por enteradas/incluidas cuando se dirigen a los "padres"; así como debemos aceptar que las autoridades educativas sí utilicen la palabra "madre" para recordarnos que es nuestra obligación velar por el rendimiento (tareas, estudio, etc.) y la presentación de nuestros hijos e hijas (uniformes, etc.), ahí sí existe la palabra "madre", para llamarnos la atención, para regañarnos, para hacernos sentir como niñas desobedientes con la tarea que la sociedad nos ha dado.

Es así como desde los primeros años en la educación formal se nos violenta e irrespeta a las mujeres, al invisibilizarnos al incluirnos en un genérico que no es tal.

Una de las formas en que esta invisibilización es reproducida y mantenida, es en los sistemas de clasificación de los materiales de las bibliotecas, no siendo la excepción el sistema de bibliotecas de la Universidad de Costa Rica, en el cual "Muchos contenidos sobre la "temática mujeres" en la colección general del SIBDI-UCR, están invisibilizados. Aunque los documentos de la colección incluya cantidad y calidad de información de interés para las mujeres, ésta no es recuperable a través de los medios usuales que tienen las personas que consultan, los ficheros manuales y las terminales" (Jiménez: 200; 276).

Jiménez (2000; 277) amplía lo anterior al expresar que desde la perspectiva de las mujeres, los lenguajes controlados que se están utilizando en el SIBDI-UCR para el análisis documental, no ofrecen la posibilidad de una adecuada indización y 
consecuente recuperación de la información. Ya que reflejan, en su lenguaje, su estructura y sus contenidos una sociedad patriarcal ... "por lo cual faltan palabras y temas que reflejen la realidad de las mujeres, sus intereses, su conocimiento, sus aportes, sus vivencias, sus carencias, falta en general, la visión del mundo de las mujeres".

Estos lenguajes controlados padecen de las consecuencias del sexismo del lenguaje corriente, por lo cual utilizan el masculino como genérico, reafirmando al hombre como paradigma de lo humano y a la vez, la subordinación de las mujeres, la presencia o ausencia significa autorización o desautorización.

Jiménez constató que en el SIBDIUCR no existen los descriptores género, perspectiva de género, o enfoque de género; no se recuperan registros con los descriptores derechos reproductivos, derechos de las mujeres, participación de las mujeres en los diferentes campos (político, social, laboral, sindical, económico, comunitario, cultural); no existen los descriptores maternidad, sexualidad, identidad femenina ni otros relacionados con el cuerpo de las mujeres; así como en relación con los términos relativos a violencia de género, sólo se identifican los términos violencia conyugal o el término general violencia, quedando invisibilizados muchos contenidos sobre diferentes tipos de violencia (2000; 279).

La principal consecuencia para la sociedad costarricense de la falta de información sistematizada en los centros de información sobre la temática mujeres, es que las políticas, la planificación y el desarrollo social se sigue basando en el conocimiento de sólo una parte de la realidad; ya que el desarrollo equitativo de la sociedad sólo se podrá dar cuando las mujeres estén plenamente reconocidas y representadas en todos los espacios y en igualdad de oportunidades con los hombres.
En el caso de la UCR las investigaciones con perspectiva de género se enfrentan con esta problemática, lo cual implica que no se conozca certeramente qué se ha investigado o estudiado sobre las mujeres, por lo cual por más rigurosos que sean los estudios del estado de la cuestión, estos siempre serán omisos por los problemas citados por Jiménez.

\section{Cada modelo de educación tiene implícito un modelo de comunicación y un modelo espacial}

Si adoptamos a la comunicación como el conjunto de formas que tienen las personas para relacionarse, podemos observar que cada modelo de educación tiene implícito, una serie de formas de relación entre los sujetos de dicho proceso.

Esto implica que en cada modelo están implícitas las conductas comunicacionales que se espera asuman quienes participan en él: por ejemplo en los modelos en los cuales las relaciones de poder que se dan son de dominación/subordinación, las conductas comunicacionales que adopten las personas serán las agresivas (emisoras) o sumisas (receptoras); mientras que en los modelos cuyas relaciones sean de cooperación, apoyo, solidaridad y respeto, las personas asumirán conductas asertivas (Smith: 1977) o niveladoras (Satir: 1991), desempeñándose como interlocutoras, no como emisoras o receptoras.

Al respecto Mario Kaplún (1985:17), afirma que "a cada tipo de educación corresponde una determinada concepción y una determinada práctica de la comunicación", y agrupa dichos modelos en tres, según la propuesta de Juan Díaz Bordenave (1976). A esta propuesta la enriquecemos con la de Garnier (1998; 11-116) sobre los modelos espaciales: 


\begin{tabular}{l|l|l}
\multicolumn{1}{c|}{$\begin{array}{c}\text { Modelo de } \\
\text { Educación }\end{array}$} & \multicolumn{1}{|c}{$\begin{array}{c}\text { Modelo de } \\
\text { Comunicación }\end{array}$} & $\begin{array}{c}\text { Modelos } \\
\text { Espaciales }\end{array}$ \\
\hline $\begin{array}{l}\text { Educación que } \\
\text { pone el énfasis } \\
\text { en los contenidos. }\end{array}$ & $\begin{array}{l}\text { Información } \\
\text { E -m->R }\end{array}$ & $\begin{array}{l}\text { Modelos } \\
\text { espaciales } \\
\text { funcionalistas. }\end{array}$ \\
\hline $\begin{array}{l}\text { Educación que } \\
\text { pone el énfasis } \\
\text { en los efectos. }\end{array}$ & $\begin{array}{l}\text { Información/ } \\
\text { persuación } \\
\text { (reglamentación). }\end{array}$ & $\begin{array}{l}\text { Modelos } \\
\text { espaciales } \\
\text { diferenciados. }\end{array}$ \\
\hline $\begin{array}{l}\text { Educación que } \\
\text { pone el énfasis } \\
\text { en el proceso. }\end{array}$ & $\begin{array}{l}\text { Comunicación, } \\
\text { proceso dialógico } \\
\text { y grupal. }\end{array}$ & $\begin{array}{l}\text { Modelos } \\
\text { espaciales } \\
\text { integrados. }\end{array}$ \\
\hline
\end{tabular}

\section{Énfasis en los contenidos}

Es el tipo de educación tradicional, basado en la transmisión de conocimientos; ubicable dentro del paradigma funcionalista positivista. Aquí el profesor es quien sabe y va a enseñar a los "ignorantes", a los que no saben.

\section{a. Modelo comunicacional:}

El modelo que pone énfasis en los contenidos tiene un concepto de comunicación como sinónimo de transmisión de información.
$\mathrm{m}$ m: mensaje, es el conocimiento.
E: emisor, es el profesor.
E -------> R
$\mathrm{R}$ : receptor, es el educando.

\section{b. Modelos espaciales funcionalistas}

El concepto espacial que se desarrolla para este modelo educativo es el funcionalista, donde se plantea un "tipo" de espacio para la actividad educación, el cual siempre debe ser de la misma forma, inflexible, direccional y jerárquico.

En este modelo se observa la preconcepción del contenido de los espacios educativos que deben respetar no sólo la relación autoritaria y jerárquica del modelo educativo, sino que supone un mismo "tipo" de espacio para la transmisión del conocimiento. Por eso es que cuando se piensa en un espacio para educación surge la idea de una aula, casi como único tipo de espacio en el cual se pueden dar los procesos educativos formales. Este tipo de aula adquiere variantes básicamente de escala, pero manteniendo su carácter impersonal, abstracto, jerárquico y direccional.

Este modelo educativo plantea los espacios de la educación tradicional:

- $\quad$ El aula como clase magistral.

- El auditorio como gran salón para transmisión masiva de información.

- Laboratorios situados en espacios idénticos o similares a las aulas y manejados como clases magistrales.

- Prácticas técnicas manuales, de la misma forma que los laboratorios.

- $\quad$ Espacios de recreación centralizados para tener control de las actividades extracurriculares por parte de los entes directores.

- Espacios de circulación como simples conectores y lo más incómodos posibles para que los educandos no puedan disfrutar de los mismos.

- Salas de audiovisuales que no cambian la relación de comunicación autoritaria y jerárquica, presentándose muchas veces como la novedad pedagógica.

En este modelo, que sigue siendo el más usado, cada espacio es una célula que se reproduce idénticamente, manejándose la relación jerárquica tanto en cada recinto o aula como en el conjunto del centro educativo.

El desarrollo de este modelo espacial funcionalista surge con las nuevas concepciones arquitectónicas producto de la revolución industrial a finales del siglo XVIII y principios del XIX, como parte del desarrollo del equipamiento social necesario para la formación y capacitación de la nueva sociedad industrializada y cuyo costo social debía reducirse al mínimo. 
Esta concepción que viene desde el siglo antepasado es la que ha dominado durante mucho tiempo los conceptos y modelos espaciales educativos, aduciéndose optimización de recursos como justificación de su uso en la práctica docente. Sin embargo, se ha demostrado y experimentado las limitaciones del uso del espacio cuando se ha querido implementar procesos educativos más participativos y democráticos en las aulas existentes.

\section{Énfasis en los efectos}

En lo que respecta a los paradigmas, se ubica dentro del funcional-estructuralismo, conocido en Psicología como conductismo. Es el que más ha influido en el concepto de comunicación más utilizado, ya que introdujo la realimentación como solución para pasar del modelo mencionado anteriormente a un modelo "supuestamente" democrático.

Al respecto Freire $(1993 ; 103)$ afirma que la perspectiva puramente idealista (a la cual también la describe como mecanicista, dogmática y autoritaria), transforma la educación en pura transmisión de "comunicados".

\section{a. Modelo comunicacional:}

En cuanto a la comunicación este modelo la concibe igual que el anterior, con una variación: se plantea que la persona que recibe el mensaje, más que recibirlo, lo "percibe" de acuerdo con su historia de vida y el momento en que esté, lo cual hace necesario conocer qué entendió del mensaje enviado, por lo cual le agrega la "realimentación":

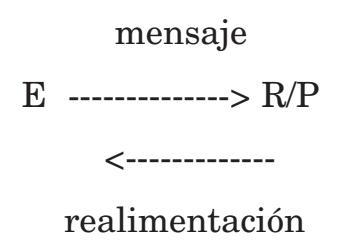

Como parte de este modelo se incluye el uso de materiales audiovisuales, se le da énfasis a las metodologías, lo cual se creyó que era suficiente para un cambio cualitativo en el proceso educativo hacia una actitud más participativa.

Se dice que la realimentación es una trampa, porque se plantea como que al incluirla el modelo se convierte de "doble vía”, y con ello ya es democrático. Por qué es una trampa? porque la realimentación sólo es la respuesta del emisor al mensaje del receptor. Ojo: sólo la respuesta al mensaje que envía el emisor, por lo cual el proceso sigue siendo autoritario, ya que el modelo se presente como lineal, se origina cuando el emisor decide enviar un mensaje y al emisor lo que le interesa conocer es sobre todo si el receptor entendió el mensaje como él se lo envía, o sea si lo entendió con las mismas intenciones e intereses del emisor.

No interesa conocer qué piensa $u$ opina el receptor sobre otros temas o situaciones, sólo la respuesta a su mensaje, por eso se llama "realimentar", porque el receptor alimenta al emisor, para que si su mensaje no es entendido o si el receptor no cambió la conducta o actitud como él le propuso, entonces el emisor decide volver a enviar el mismo mensaje o la misma idea, pero con otra presentación.

La realimentación no elimina los roles de emisor y receptor, sólo incluye al modelo anterior la respuesta del receptor, pero los roles siguen siendo los mismos y las relacione de poder también.

Este modelo surge como parte del proceso del desarrollismo y de la revolución verde en agricultura, en el cual se plantea que los países pobres o subdesarrollados se desarrollarán si adoptan la tecnología producida por las países desarrollados. Por lo cual se considera que ya no es suficiente que los educandos demuestren si aprendieron o no los conocimientos, por medio de exámenes, sino que se incluye la enseñanza con el método 
"aprender haciendo", porque se considera que además de tener la información, debe adiestrársele técnicamente, por lo cual se incluye la tecnología audiovisual, para presentar la información de una forma más gráfica, y se incluyen los talleres y demostraciones.

A nivel de la Psicología se plantea el cambio de actitud, la reingeniería del comportamiento, ya que se considera que el subdesarrollo es un problema de actitud, por lo cual hay que enseñarle a las personas cómo actuar y esto se logra si además de darles el conocimiento se les adiestra en cómo utilizar dicho conocimiento. Esta propuesta educativa es implementada en todos los campos, por ejemplo en agricultura con la introducción de la mecanización, de variedades mejoradas y de los agroquímicos; a nivel de salud con las campañas educativas para enfrentar pandemias y las campañas de vacunación.

Las conductas comunicacionales que asuman las personas que participan en procesos en los cuales se presenten con mayor frecuencia estos modelos, serán las catalogadas como agresivas (emisoras) o sumisas (receptoras/perceptoras).

\section{b. Modelos espaciales diferenciados}

Se fundamenta en la teoría general de sistemas, dándole una importancia relativa a las relaciones entre los elementos del sistema y a su posición relativa en el sistema, manifestándose una diferenciación funcional y jerárquica de las partes en relación al todo.

El desarrollo de esta concepción del espacio define el

\footnotetext{
"sistema como un conjunto de objetos más las relaciones entre esos objetos y entre los atributos de los objetos. Los objetos son las partes o componentes del sistema y pueden ser de muchos tipos como abstractos, conceptuales o concretos. Los atributos son propiedades de los objetos y las relaciones de un sistema, son las posiciones relativa (relaciones estáticas) que estructuran el sistema y las interrelaciones
}

(relaciones dinámicas) que comunican y dan cohesión al sistema" (Racionero: 1978; 14).

Este modelo se caracteriza por el acondicionamiento social, la programación social, la manipulación. Con él:

- Se busca optimizar el uso de los espacios de acuerdo a las necesidades de las actividades para las cuales se plantea, desarrollando diferentes funciones a las partes del sistema, aunque en el interior de cada una de ellas se sigue manteniendo la actitud jerárquica y autoritaria.

Se pretende que cada una de las partes del sistema cumpla una función específica y particular para que el todo funcione adecuadamente, de manera que se busca condicionar los comportamientos espaciales de acuerdo a las características de cada uno de los espacios, creando la sensación de una gran democratización a través de una mayor variedad de espacios diferenciados, cuando lo que se busca es más bien predeterminar las funciones de un sistema y que cada usuario cumpla su labor de acuerdo al programa inicial.

- Se busca CONDICIONAR al usuario, a través del modelo espacial, de manera que se le ofrece mayor diversidad aunque sin ningún tipo de decisión en el proceso, simplemente se es una parte más del sistema.

En América Latina, la implementación de estos modelos espaciales, correspondientes a una educación que le da énfasis a los efectos, se da a través de los programas desarrollistas con el surgimiento de planteamientos como los de CONESCAL (Centro Regional de Construcciones Escolares para América Latina y el Caribe) (CONESCAL, 1973), y los planteados por teóricos de la planificación educativa, en 
donde se busca el desarrollo de unidades escolares con espacios diferenciados en su conjunto, a través de un proceso de planificación detallado y centralizado, donde la diferencia entre espacios radica en el número de metros asignados por estudiante según una actividad particular.

En este modelo espacial los espacios para la acción educativa se presentan como:

- Aulas de clase magistral de diferentes tamaños, de acuerdo a la disciplina del contenido impartido. Se asigna un número de metros cuadrados por estudiante, proyectado según la disciplina y los contenidos.

- Auditorios como salones de alta concentración y con la facilidad de poder presentar diferentes actividades, ya sea una conferencia, teatro, música, etc. Aunque se sigue manteniendo el carácter de actividad básicamente informativa y direccional.

- Laboratorios diferenciados y talleres de prácticas diferenciados por el tipo de manipulación, según la actividad.

- Salas individuales de estudio o de grupos pequeños, ante el desarrollo del trabajo individual y de grupo que presenta esta opción pedagógica, con el fin de desarrollar la especialización dentro de las especialidades.

- Áreas de recreación diferenciadas para actividades de esparcimiento libre o áreas de concentración masiva.

- Espacios de circulación que sirven como conectores entre áreas académicas y no académicas.

- Incorporación de los sistemas audiovisuales a los salones de clase, laboratorios, auditorios, etc.

Este modelo espacial es el que promueve la idea de los espacios multiuso -por una parte- y los espacios especializados por otra, de manera que se establecen relaciones de interdependencia entre todos los espacios del conjunto educativo, según lo previsto en los procesos de planificación centralizada.

En este modelo cada uno de sus espacios son parte de un sistema que debe funcionar como un todo orgánico e interdependiente y planificado previamente y de manera centralizada y autoritaria. Es importante el acondicionamiento del usuario a través del espacio, y responde a la relación causa-efecto, manifiesta en el modelo educativo basado en los efectos.

\section{Énfasis en los procesos}

Este modelo se generó básicamente en América Latina, con aportes de pensadores de otras latitudes, siendo uno de sus ideólogos Paulo Freire con su "Pedagogía del oprimido" y "Pedagogía de la esperanza", como instrumentos para la transformación de la sociedad.

\section{a. Modelo comunicacional}

Con respecto a la comunicación este modelo la ve como: diálogo, intercambio, relación de compartir, de hallarse en correspondencia, en reciprocidad (Freire, 1973; 64). La comunicación se concibe como proceso social, continuo y permanente, entre interlocutores, no entre emisores y receptores o perceptores.

Este modelo es participativo, ya que plantea que solo así se puede aprender: errando y rehaciendo. Para lograr la participación se deben desarrollar diálogos constantes entre todos los actores del proceso, participación que llegará hasta la toma de decisiones por consenso o mayoría.

Freire $(1993 ; 105)$ amplía su propuesta afirmando que "No hay educación sin enseñanza, sistemática o no de algún contenido". Explica que el problema fundamental, de naturaleza política, está coloreado por tintes ideológicos, a saber, quién elige los contenidos, a favor de quién y de qué estará su enseñanza, contra quién, a favor de qué, contra qué. Qué papel le corresponde 
a los educandos en la organización programática de los contenidos; cuál es el papel, en otro nivel de los y las que en las bases están involucrados en la práctica educativa de la escuela; cuál es el papel de las familias, de las organizaciones sociales; de la comunidad local".

A lo anterior propone democratizar el poder de elección de los contenidos así como el modo más democrático de tratarlos y agrega que no es posible democratizar la elección de los contenidos sin democratizar su enseñanza (Freire: 1993; 105).

Lo que no es posible en la práctica democrática es que el profesor o profesora, subrepticiamente o no, imponga a sus alumnos su propia "lectura del mundo", en cuyo marco se sitúa la enseñanza del contenido. Luchar contra el autoritarismo de izquierda o de derecha no me conduce, sin embargo, a una neutralidad imposible que no es otra cosa sino el modo mañoso con el cual se pretende esconder la opción. El papel del educador o de la educadora progresista que no puede ni debe omitirse, al proponer su "lectura del mundo", es señalar que existen otras "lecturas del mundo" diferentes de la suya y hasta antagónicas en ciertas ocasiones (Freire: 1993; 107). Y afirma que la democratización de la sociedad implica la democratización de la escuela (contenidos y su enseñanza).

Las conductas comunicacionales que asuman las personas que participan en procesos en los cuales se presente con mayor frecuencia este modelo son conductas asertivas (Smith: 1977) o niveladoras (Satir: 1991), desempeñándose como interlocutoras de procesos dialógicos (Apatow: 1998), no como emisoras o receptoras.

Satir (1991: 107-108) afirma que la conducta niveladora permite resolver rupturas, abrir callejones sin salida o construir puentes de unión entre personas; es la persona que sabe lo que hace y está dispuesta a afrontar las consecuencias, se disculpa al darse cuenta de que hizo algo no intencionado y que es capaz de criticar y evaluar actos sin culpar a las personas, en resumen es la persona que es coherente entre lo que dice y lo que hace.

\section{Diálogo}

El diálogo se plantea como la alternativa a las conductas comunicacionales agresiva/sumisa. Aunque esta palabra se emplea continuamente, su definición teórica y su operacionalización no son tan sencillas. Es por ello que recurrimos a Paulo Freire para concretarla en los procesos educativos.

Este autor afirma que el diálogo entre docentes, alumnas y alumnos no los convierte en iguales, pero marca la posición democrática entre ellos y ellas. Dice que los profesores no son iguales a los alumnos por $\mathrm{n}$ razones, entre ellas porque la diferencia entre ellos los hace ser como están siendo, ya que si fuesen iguales uno se convertiría en el otro.

Expresa que el diálogo gana significado precisamente porque los sujetos dialógicos no sólo conservan su identidad, sino que la definen y así crecen uno con el otro. Por lo mismo el diálogo no nivela, no reduce el uno al otro; la relación dialógica no anula, como se piensa a veces, la posibilidad del acto de enseñar. Por el contrario, funda ese acto, que se completa y se sella en el otro, el que aprende (Freire: 1998; 112).

Agrega que por el contrario, cuando el pensamiento crítico del educador o de la educadora se entrega a la curiosidad del educando, si el pensamiento del educador o de la educadora anula, aplasta, dificulta el desarrollo del pensamiento de los educandos, entonces el pensar del educador, autoritario, tiende a generar en los educandos sobre los cuales incide un pensar tímido, inauténtico, o a veces puramente rebelde (Freire: 1998; 113).

Explica que el mal no está en la clase expositiva, en la explicación que el profesor o la profesora den, sino que está en aquel tipo de relación educador-educando 
en que el educador se considera único educador del educando, en que el educador rompe o no acepta la condición fundamental del acto de conocer que es la relación dialógica; la relación en que el educador transfiere el conocimiento sobre a o b o c objetos o contenidos al educando, considerado simple recipiente (Freire: 1998; 113).

El diálogo surge como la forma de establecer las relaciones en procesos educativos en los cuales la educación pasa de ser un proceso individual a ser un proceso grupal. Modelo en el cual el profesor o la profesora pasa de ser el eje a ser la persona que facilita, estimula el proceso de búsqueda, para problematizar, para ayudar al grupo a que se exprese y aportarle la información que necesita para que avance. Ello por cuanto este modelo exalta los valores comunitarios, la solidaridad, la cooperación; exalta la creatividad, el valor y la capacidad potencial de toda persona (Kaplún: 1985).

\section{b. Modelos espaciales integrados:}

Estos modelos espaciales corresponden al modelo educativo cuyo énfasis se da en los procesos, por lo que se debe plantear un proceso de concepción, asimilación, apropiación y desarrollo del espacio, de la manera más participativa y democrática posible.

Para sustentar este planteamiento es que se analizan los principios del "Modo intemporal de construir" (Alexander: 1983; 11-13), a través de un lenguaje de patrones y teniendo como principios rectores prácticos:

- $\quad$ El orden orgánico: tiene como fin que los procesos de planificación y construcción de los espacios permitan al todo emerger a partir de los actos locales, de manera que se manifieste el criterio general por más particular que sea el hecho acaecido.

- La participación: busca que todas las decisiones de lo que se va a construir y cómo se va a construir, deben estar en manos del usuario, en este caso del educando-educador.

- El crecimiento a pequeñas dosis: plantea que el desarrollo de una obra debe mesurarse dentro de cada etapa, tendiendo a proyectos lo más pequeños posibles, para tener el control tanto administrativo como participativo.

- $\quad$ El desarrollo de patrones espaciales: pretende que el diseño debe guiarse a través de una colección de principios de planificación, comunitariamente adoptados, creados o desarrollados, pero que emerjan de la misma comunidad.

- La diagnosis continua y permanente: exige que toda la labor participativa y democrática debe protegerse con un diagnóstico anual, expresando con detalle cuáles espacios tienen validez y cuáles no en cualquier momento de la historia de la comunidad.

- La coordinación de su desarrollo: tiene como fin plantear mecanismos reguladores del proceso de conformación y transformación de los espacios sociales participativos y democráticos.

Estos principios buscan una mayor participación del usuario en la conformación del espacio social, no solo en el momento de su utilización, sino que también en los momentos de gestación y de administración de los mismos, ya que el ambiente mismo sería parte del proceso de aprendizaje de los educandos.

Este modelo espacial se fundamenta en el respeto por el contexto natural y humano, así como de la historia particular de las comunidades, donde las decisiones de cómo y qué se construye es producto de un proceso participativo y democrático.

Aquí el espacio se ve como proceso social, continuo y permanente, no impuesto ni 
jerarquizado por terceros, y en educación el mismo espacio se convierte en objeto de estudio y de conocimiento de las disciplinas. Es por esto que los patrones espaciales planteados para el desarrollo de este modelo espacial integrado son los siguientes:

- De concentración colectiva, dirigida o espontánea, que responda a actividades informativas formales e informales.

- De concentración grupal, dirigida y espontánea, que responda a la exposición dialógica y discusión dirigida.

- De concentración individual, dirigida y espontánea, que responda a la discusión dialógica y a la participación grupal espontánea y creadora.

- De entorno vivencial, pasivo y activo, que responda a la observación grupal y a la manipulación ligera.

- De vitalidad ambiental, pasiva y activa, que responda a la participación transformadora grupal y a la manipulación pesada.

- De ámbito de intercambio, específico y general, que responda a los procesos de autoinformación y autorreflexión, así como de información dirigida.

- De ámbito transformador, específico y general, que responda a procesos de intercambio de información de manera espontánea, tutorial o libre.

Según estos patrones espaciales, el proceso de aprendizaje se daría dentro de estas características de organización del uso del espacio, por lo que el usuario debe ser considerado como parte del proceso de aprendizaje y debe participar activamente en la concepción, conformación, asimilación y desarrollo del proceso de construcción de los espacios para el aprendizaje.

Una educación basada en procesos debe tener un espacio que corresponda a esos fines, porque lo que busca es el desarrollo del ser humano integralmente y no masiva ni diferenciadamente, se busca integrar no las funciones, sino los procesos de concepción, asimilación, apropiación, desarrollo y control del espacio como entorno vivencial que debe contener una vitalidad: social e individual, activa, participativa y democrática.

\section{Programadas pero no determinadas}

La escuela, aún cuando uno de sus roles en tanto institución es la reproducción de las relaciones de clase y de dominación, sus agentes (principalmente maestros y profesores) pueden actuar para cambiar estos objetivos, a fin de darles las mejores posibilidades a todos los niños y niñas, mientras que los niños, por su parte, también pueden imponer algunas de sus necesidades e intereses (Vásquez: 1996; 24).

\section{La institución educativa socializa tanto a los estudiantes como a los docentes:}

La institución escolar constituye una cultura en el sentido de que está estructurada en torno a un conjunto de valores que le son propios y que actúan globalmente sobre sus miembros contribuyendo a su socialización (tanto de los niños como de los adultos) (Vásquez: 1996; 42).

Para variar dichas relaciones debemos tomar conciencia de los valores que estructuran cada institución en particular, así como los mecanismos a través de los cuales actúa esa cultura.

La estructura de la sociedad patriarcal programa a los seres humanos para asumir de una forma inconsciente conductas agresivas/sumisas, dominantes/subordinadas, pero a pesar de que estamos programados no estamos determinados, como lo retoma Freire (1998; 94).

“... aunque "programados”, no estamos sin embargo determinados; es por estar siendo así por lo que 
hemos venido desarrollando la vocación para la humanización y que tenemos en la deshumanización, hecho concreto en la historia, la distorsión de la vocación".

Como seres humanos y con mayor razón como educadores seguimos el sueño de la humanización, "cuya concreción es siempre proceso, siempre devenir, pasa por la ruptura de las amarras reales, concretas, de orden económico, político, social, ideológico, etc., que nos están condenando a la deshumanización" (Freire: 1998; 95).

Según la siguiente afirmación de Freire, las mujeres debemos de liberarnos de las relaciones de poder dominación/subordinación, "Como individuo y como clase, el opresor no libera ni se libera. Liberándose en y por la lucha necesaria y justa, el oprimido, como individuo y como clase, libera al opresor, por el simple hecho de impedirle continuar oprimiendo" (Freire: 1993; 95).

"Las investigaciones más recientes acerca del estilo de administración favorecen más a las mujeres que a los hombres. La teoría Z y el enfoque participativo, están asociados con los estereotipos femeninos y plantea un modelo de autoridad como una forma de influencia y control social democrático, que toma en cuenta el comportamiento cooperativo, es decir la cultura organizativa" (Vargas: 1997; 186).

El poder reconceptualizado desde una perspectiva de género, tiene sus raíces en una clase de interacción, negociación y mutualidad descriptiva de la organización profesional. Es un poder facilitador, como lo denomina Dunpal, D. y Goldman, P. (1991) y Lagarde, M. (1993, 1995), es un poder de afirmación, es un modelo más democrático, que frecuentemente es más utilizado por las mujeres que por los hombres (Vargas: 1997; 193).

El "poder facilitador" refleja un proceso que favorece una condición creadora, que permite a los subordinados y las subordinadas realizar sus ejecuciones laborales individuales y colectivas y se manifiesta por medio de los otros y las otras. En este sentido la administración educativa ejerce este poder cuando se compromete en sus actividades a brindar su soporte, cuando selecciona y maneja a las personas que van a trabajar juntas, prestando atención a las características de personalidad y a sus habilidades, además de proporcionar entrenamiento, y una conducta colaboradora. Por otra parte, monitorea y supervisa las actividades, no con el objeto de ejercer un control jerárquico, sino para brindar retroalimentación y realizar sugerencias ... la administradora y administrador deben aprender a ejercer el poder sobre la base de la confianza y la reciprocidad profesional (Vargas: 1997; 194).

Desde esta perspectiva se cambia la premisa "el poder ejercido sobre otros y otras o de dominio" por "el poder a través de otros y otras, de afirmación" (Vargas: 1997; 194). "La resocialización femenina hace posible que la mujer reconozca sus deficiencias dentro del mercado laboral y aprenda cómo ser más asertiva (en comunicación/relaciones), cómo ser una buena administradora, cómo comunicarse más eficientemente y cómo tomar decisiones. Todo ello, conlleva a desarrollar una más alta auto-estima y lidiar con las habilidades y el lenguaje adecuado para cada situación laboral"...

Es un aprender a cultivar técnicas para el buen desarrollo profesional, desde una postura autoafirmativa, autogenerativa, auto-confiada, sin tener ese miedo a la competencia, a salvar los obstáculos para vencer en el mundo público, en el campo administrativo, en la institución escolar.

\section{Reinventar el poder:}

Uno de los elementos fundamentales de cualquier cambio que se quiera dar en la sociedad actual es el de las relaciones de poder, ya que si se hace el cambio específico que se pretenda, sin tomar en cuenta el tipo de relaciones con el cual se lleve a cabo el cambio y el tipo de relaciones que 
sustentarán el proceso de cambio, sin tomar en cuenta el uso del poder, este cambio tarde o temprano se frustrará y se dará un retroceso negativo.

Lo anterior se da por cuanto toda actividad humana se basa en las relaciones de poder y si estas no se visibilizan, lo que pasa es que se reproducen las relaciones dominación/subordinación características de la sociedad actual, con lo cual el cambio que se haga será cosmético, no implicará un cambio en el fondo, lo cual lleva a realizar cambios en aspectos específicos, como en la educación, pero utilizando los mismos métodos autoritarios, directivos; con lo cual el cambio no se logrará, ya que implicará hacer lo mismo pero de diferente forma.

Los procesos de democratización que se impulsan sin tomar muy en cuenta las relaciones (comunicación) que los sustentarán, caen en procesos autoritarios con cara de democracia, porque quienes participan lo hacen desarrollando relaciones de dominación/subordinación, porque es así como se saben relacionar y creen que esta es la única forma de hacer las cosas.

Freire $(1998 ; 189)$ propone que uno de los aspectos fundamentales para la posmodernidad de izquierda es el tema del poder, el tema de su reinvención que trasciende el de la modernidad, el de su pura conquista. Ya que expresa que no siempre la victoria total de la revolución evita que ella se pierda más adelante y que a veces se pierde en pleno goce de su poder, que ella simplemente conquistó pero no reinventó, no recreó. Se pierde por el exceso arrogante de certeza en sus certezas, por la consecuente falta de humildad, por el ejercicio autoritario de su poder.

\section{Perspectiva de género:}

Esta investigación se inscribe en la perspectiva de género, por varias razones, entre ellas destacan dos: se estudiarán los comportamientos tanto de las mujeres como de los hombres que participan en el proceso educativo; y segundo, se elaborarán propuestas que permitan establecer relaciones que superen las relaciones de poder, por relaciones de cooperación, apoyo y solidaridad.

Lo anterior implica que se analizarán los comportamientos tanto de las mujeres como de los hombres que participen en los procesos educativos que se estudiarán, desde la perspectiva de género, lo cual implica que se incluirá también a los hombres, tanto porque ellos también tienen género como porque la teoría de género es relacional, se plantea entender a cada sujeto de género, pero entenderlo en su relación, en su dialéctica (Lagarde: 1994; 42). Ello implica estudiarlo tanto en su comportamiento producto de su género, como en su comportamiento de acuerdo con el rol que desempeñe en el proceso educativo, por cuanto las personas asumen conductas de acuerdo con los roles sociales que desempeñen, lo cual implica que no siempre las relaciones de dominación son ejercidas por hombres y las de subordinación por mujeres.

Según Lagarde la perspectiva de género es una acción directa sobre la sociedad basada en la explicación de estas teorías de género, sobre todo en el hecho de que es posible cambiar, pero desde posiciones políticas bien concretas y agrega que esta perspectiva también lleva a intervenir con una voluntad activa en la construcción de alternativas no opresivas de género (Lagarde: 1997; 43).

El feminismo se opone al poder SOBRE las personas y propone, en vez, el poder DE las personas sin intermediarias. (Facio: 1994; 27).

\section{Referencias bibliográficas}

Alexander. Chistopher. Urbanismo y Participación. Barcelona. Colección Punto y Línea, Editorial Gustavo Gili, 1983. 
Apatow, Robert. El arte del diálogo. España. EDAF, S.A. 1998.

Arellano-Osuna, A. “¿Qué estamos haciendo en América Latina para desarrollar lectores y escritores autónomos?" En: Memoria del Segundo Congreso de las Américas sobre Lectoescritura. Heredia, Costa Rica: Universidad Nacional, Dirección de Extensión, 1996.

Batres, Gioconda y otras. Compiladoras. Manual de lecturas para cursos en violencia doméstica de las academias de policía. Costa Rica: ILANUD. 1996

Calero Fernández, Ma. Ángeles. Sexismo lingüístico. Análisis y propuestas ante la discriminación sexual en el lenguaje. Madrid, España: Narcea, S. A. de Ediciones. 1999.

Chaves, Lupita. Proyecto: "Develando la acción pedagógica para transformarla”. III Informe parcial. Anexo I: Respuestas a preguntas de investigación. Costa Rica. Marzo 2001.

Claramunt, María Cecilia. Casitas quebradas. El problema de la violencia doméstica en Costa Rica. Costa Rica: EUNED. 1997.

COVESCAL. 30. Revista. Revista especializada en construcciones escolares. México: Centro Regional de Construcciones escolares para América Latina y el Caribe. Dic. 1973.

Díaz Bordenave, Juan. "Las nuevas pedagogías y tecnologías de comunicación". Ponencia presentada a la Reunión de Consulta sobre la Investigación para el Desarrollo Rural en Latinoamérica. Cali, Colombia. 1976.
Facio Montejo, Alda. "Cuando el género suena cambios trae". En: Programa Interdisciplinario de Estudios de Género. Introducción a los estudios de género: categorías básicas de análisis y el sistema sexo-género, como expresión de relaciones de poder. Managua, Nicaragua: Lecturas 1 . Universidad Centroamericana. 1994.

Freire, Paulo. Pedagogía del oprimido. México: Siglo XXI Editores. 1973.

Pedagogía de la esperanza. México: Siglo XXI. 1998.

Izquierdo, Ma. Jesús. "Un marco teórico para las relaciones de sexo y de género". En: Luna, Lola (Comp.) Mujeres y Sociedad. Nuevos enfoques teóricos y metodológicos. España: Universitat de Barcelona. 1991.

Jiménez Gamboa, Ana Cecilia. El sexismo en los lenguajes controlados. Tesis presentada en el Posgrado en Estudios de la Mujer, Universidad de Costa Rica/Universidad Nacional. Costa Rica. 2000.

Kaplún, Mario. El comunicador popular. Quito, Ecuador. Editorial Belén. 1985.

Lagarde, Marcela. Género y feminismo. Desarrollo humano y democracia. España: Horas y HORAS la editorial. 1997.

.Género, teoría de género y perspectiva de género". En: Programa Interdisciplinario de Estudios de Género. Introducción a los estudios de género: categorías básicas de análisis y el sistema sexo-género, como expresión de relaciones de poder. Lecturas 1. Managua, Nicaragua: Universidad Centroamericana. 1994. 
Lamas, Marta. "Para una definición de la 'cuestión del género". En: Programa Interdisciplinario de Estudios de Género. Introducción a los estudios de género: categorías básicas de análisis y el sistema sexo-género, como expresión de relaciones de poder. Managua: Universidad Centroamericana. 1994.

Mañeru Méndez, Ana. "Lenguaje en la escuela: sexismo en el lenguaje". En: Infancia y sociedad. Revista de Estudios No. 10. Julio-Agosto. España: Ministerio de Asuntos Sociales. 1991.

Pearce, Barnett. "Nuevos modelos y metáforas comunicacionales: el pasaje de la teoría a la praxis, del objetivismo al construccionismo social y de la representación a la reflexividad". En: Fried S., Dora. Nuevos paradigmas, cultura y subjetividad. Argentina: Paidós. 1994.

Pérez, Rafael Ángel, y otros. Los procesos de enseñanza y aprendizaje en una sociedad democrática. Costa Rica: Centro Nacional de Didáctica. Ministerio de Educación Pública, Imprenta Nacional. 1991.

Racionero, Luis. Sistemas de ciudades y ordenación del territorio. Madrid: Alianza Editorial. 1978.
Real Academia de la Lengua Española. Diccionario de la lengua española. Madrid, España. 1994.

Sánchez, Ana. "La masculinidad en el discurso científico: aspectos epistemológico-ideológicos". En: Luna, Lola (Comp.) Mujeres y Sociedad. Nuevos enfoques teóricos y metodológicos. España: Universitat de Barcelona. 1991.

Schwartz, B. Queuing and waiting. Chicago y Londres: University of Chicago Press. 1971.

Vásquez B., Ana. Martínez, Isabel. La socialización en la escuela. Una perspectiva etnográfica. España: Paidós. 1996.

Villarreal, Ana Lucía. Principios de comunicación rural: antología. 1. Ed. Costa Rica: EUNED. 1994.

Relaciones de poder. Mujeres en la encrucijada entre trabajo productivo y trabajo reproductivo. Tesis de Maestría en Sociología, Universidad de Costa Rica. 1999.

Villarreal, Ana Lucía y Garnier, José Enrique. "La comunicación y el espacio en los procesos educativos". En: Revista Herencia. Volumen 7, No. 2 y Volumen 8, No. 1. 1995-1996. Vicerrectoría de Acción Social, Universidad de Costa Rica.

Ana Lucía Villarreal Montoya Investigadora del IIMEC. Universidad de Costa Rica 